is done. In the mid-1980s Aaron and Schwartz found the rate of coronary artery bypass grafts to be one sixth the rate in the United States. ${ }^{5}$ After correcting for population differences British surgeons performed half as many inguinal hernia repairs as United States surgeons in 1987 and one sixth as many prostate resections. On the other hand, British surgeons still perform $20 \%$ more tonsillectomies. ${ }^{46}$

Radiology is used more sparingly as well. Hospital patients get half as many radiographs as their American counterparts. Computed tomography comparisons are legion. Britain had $2 \cdot 4$ scanners per million people in 1988 , many of them bought by private fund raising campaigns. ${ }^{7}$ In a typical American state the rate exceeds 18 per million. (Even that number underestimates the true number of scanners in the United States: many radiologists have scanners in their offices and run mobile scanning services, none of which are reported in statistics (personal communication).) American patients with symptoms of stroke typically get a computed tomography brain scan on admission to hospital and four days later. British patients, if stable, are usually observed and placed on aspirin, with scanning done several days later, when ischaemic lesions become apparent.

\section{The waiting lists and the old NHS}

Critics say courtesy and frugal use of technology are not enough. The mass media have reported on children dying with heart defects after being turned away from hospitals that had closed beds to save money. Other reports have featured patients dying in accident and emergency waiting rooms or while waiting for ambulances. ${ }^{8 \cdot 11}$ All this media coverage has been summarised into the infamous hospital waiting list, the political unit of measure of NHS hospitals' inefficiency.
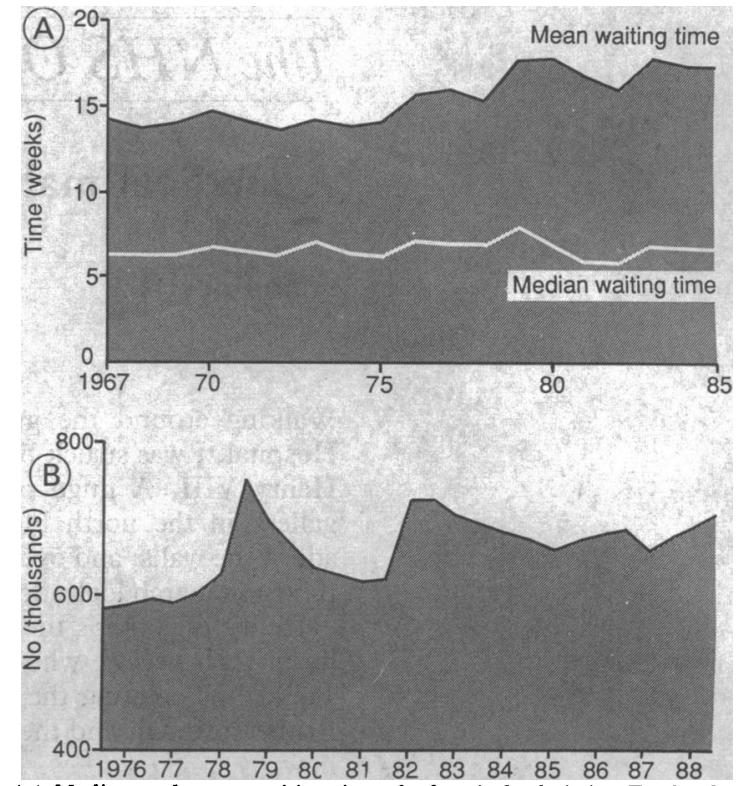
(a) Median and mean waiting times for hospital admission England and Wales 1967-81, England 1982-5. (b) Cases on NHS inpatient waiting lists England 1976-89

Between 600000 and 800000 Britons wait a mean of about four months for non-emergency operations such as hip replacements, hernia repairs, gall bladder removal, and cataract replacements. ${ }^{12}$ And, although median waiting times run at about five weeks, one surgeon acknowledged that he had patients waiting a year to see him, after which they would get put on a list to wait another year for their hip replacement.

Until the white paper was published waiting list politics ran a predictable course. When lists got long the public and press complained and the government

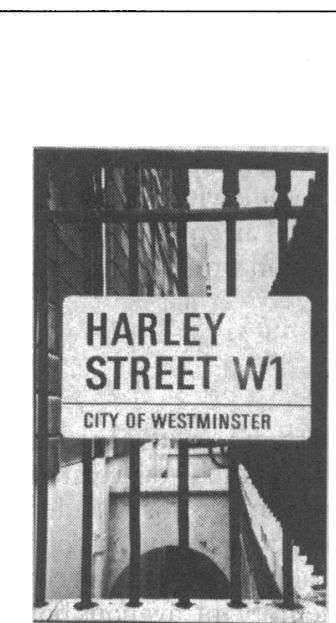

\title{
Private medicine: the NHS's safety valve
}

Harley Street in London is orderly, Victorian, and a bit understated for the lucrative symbol it represents. The only obvious signs of wealth are the glossy black doors and polished brass nameplates that list the scores of doctors that practise privately there.

Just over 1 in 10 Britons is covered by private medical insurance. (The comparable United States figure is about $70 \%$, though true comparisons are fraught with confounders: some United States patients carry multiple policies or are partly covered by government schemes.) Most live in or near London, and almost all are covered by one of three insurers: British United Provident Association (BUPA), Private Patients Plan, or Western Provident Association. Total spending by private insurers has been growing by $10-15 \%$ a year and last year topped $£ 1200 \mathrm{~m}$, about $4 \%$ of NHS spending.'

About $85 \%$ of London consultants do some private practice, most of them in surgical or invasive medical specialties, such as orthopaedics, obstetrics-gynaecology, and gastroenterology. A smaller percentage of those outside London practise privately. Actual salaries are difficult to estimate, since the NHS has decided that such matters are between doctors and their tax men.

In 1988, however, 15134 consultants practised in Britain. ${ }^{2}$ Private insurers reported paying to physicians and surgeons

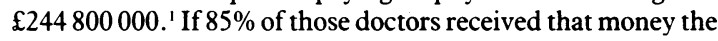
mean would be $£ 19030$ - an estimate that is necessarily low. A London surgeon, who refused to name his exact income, did say that his earnings from his $10 \%$ private practice well exceeded his NHS basic pay and merit award.

Private practice in Britain seems to deliver what American private practice promises: a free market for patients who can pay. Firstly, it provides an alternative for patients who prefer to avoid the NHS. Typical private subscribers-young and middle aged managers and professionals and their families- prefer to choose their doctors and do not wish to queue up for elective procedures. ${ }^{3}$ In addition, private abortion services give an option to women who are uncomfortable terminating their pregnancies through their general practitioners.

Top 10 procedures: $B U P A$ and NHS

\begin{tabular}{lcr}
\hline & \multicolumn{2}{c}{ Rank } \\
\cline { 2 - 3 } Procedure & BUPA & NHS \\
\hline Removal of impacted teeth & 1 & 9 \\
Upper gastrointestinal tract endoscopy & 2 & 13 \\
Dilatation and curettage (includes abortion) & 3 & 1 \\
Skin lesion excision & 4 & 22 \\
Total abdominal hysterectomy & 5 & 5 \\
Insertion of tympanic membrane tubes & 6 & 21 \\
Endoscopic examination of ovaries & 7 & 14 \\
Inguinal hernia repair & 8 & 7 \\
Cystoscopy & 9 & 3 \\
Breast lesion biopsy & 10 & 42 \\
\hline
\end{tabular}

Secondly, private medicine provides a service sometimes not delivered in the NHS: "To put it rather crudely," Sir Thomas Holmes Sellors once said, "In an [NHS] outpatient session the patient listens to the doctor, whereas in private practice the consultant listens to the patient." (Critics, however, say that private hospitals often fail to provide other basic medical services: resuscitation equipment, for example, is far from universal.)

Finally, private insurance injects a few more pounds into an underfunded national medical system. Insurance executives say the money pays for a few more procedures, which indirectly keeps NHS waiting lists shorter.

But critics, especially the Labour Party, say the opposite is true: consultants maintain long NHS waiting lists to sustain patients' demands for their private practices. The charge 
acted: hospital administrators were told, "Cut your lists-or else."

The quickest way to shrink a waiting list is to close beds. Under the topsy turvy economic rules of the NHS a full bed is costly; an empty bed is not. The more empty beds a hospital produces the more money can be saved and spent elsewhere-on patients waiting for new hips or hernia repairs. Patients still come in with infections and infarctions, however, and they must be admitted to hospital.

At Queen's Medical Centre an influenza outbreak last winter sent acutely ill patients to obstetric, orthopaedic, ear, nose, and throat, and general surgery wards, where nurses are not trained to deal with pneumonia and heart failure. Doctors' efficiency dropped as well, because their patients were spread over a hospital that is a quarter mile long on each side. At St Thomas's Hospital, a world famous institution just across the Thames from the Houses of Parliament and the Department of Health, bed closures left a third of its 1000 beds lying empty last autumn.

It is not only beds that cost money in the NHS: anything that is done for patients is money spent. For example, at St Thomas's money was pulled together to buy a lithotripter. But then it stood idle because it was too expensive to use-even though it would have prevented costlier surgery.

Long waiting lists and underused technology are truly foreign to a doctor from America, where a full bed and a busy lithotripter create profits for a hospital. But those examples only highlight the underlying differences between British and American hospitals and their doctors. Among others are the following.

No one oversees consultants-"Across very broad areas of NHS activity there is no direct assessment of the extent of cure or care or improvement achieved," according to one survey. ${ }^{13}$
Budgeting systems have operated to deter innovationAny money that has been saved during the year must be returned to the health authority, and spending across departments can be difficult. Planning becomes almost comical. Surgeons at Queen's Medical Centre tried to buy a laparoscope, but their department couldn't save the $£ 100000$ needed. Fortunately, delays in installing a new burglar alarm system left the hospital with $£ 300000$, a third of which bought the laparoscope.

Doctors are not attuned to money they spend- "Since I was never accountable, I never thought about what I was spending," said a general physician at Queen's. "But it is my moral responsibility to think about money, because NHS or not, patients do pay for what we do."

Hospitals have been run for doctors, not patients-An administrator described a district hospital that hired a surgeon with interests in neurosurgery. Though there was little local demand for such work, several beds were apportioned to it simply because of the surgeon's interest.

Consultants' appointments are virtually lifelong, and entrance into consultancy is closely guarded by both the profession and the government. "Lifetime appointments make us a terribly difficult group to manage," said a London surgeon.

But all is not bad in British hospitals. Frugal use of technology makes them safer places than American institutions, doctors argue. Some liabilities become assets as well when looked at from patients' perspectives.

Clinical freedom protects patients, as well as doctors. "No one can stand at the bedside and tell me how much I can spend to help a patient," said a surgical registrar. "No bureaucrat or government rule can come between us. My duty is simple: it is to my patient. You

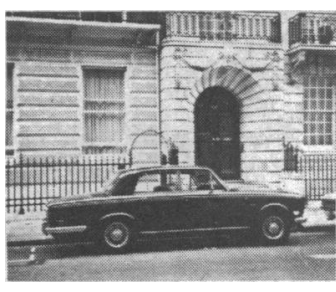

reflects topsy turvy NHS economics. "No industry, except the NHS, allows its central workers to go into business against their own company," said an administrator.

Consultants deny they are so savvy economically. A London surgeon recounted: "An American doctor said to me that we consultants are lazy, that if we 'got with it' we could work hard and make more money. We aren't entrepreneurs. And even in private practice we don't have to be because of the waiting lists. Being brash and undercutting the next person isn't in our national character." Two commissions have studied the relationship between longer NHS waiting lists and the growth of private practice. Neither found an association. ${ }^{3}$

Given that private medicine provides more options and shorter queues I was puzzled that only $10 \%$ of Britons are covered. One patient, a business executive who chose the NHS, explained: "Why go private? All I would get would be a

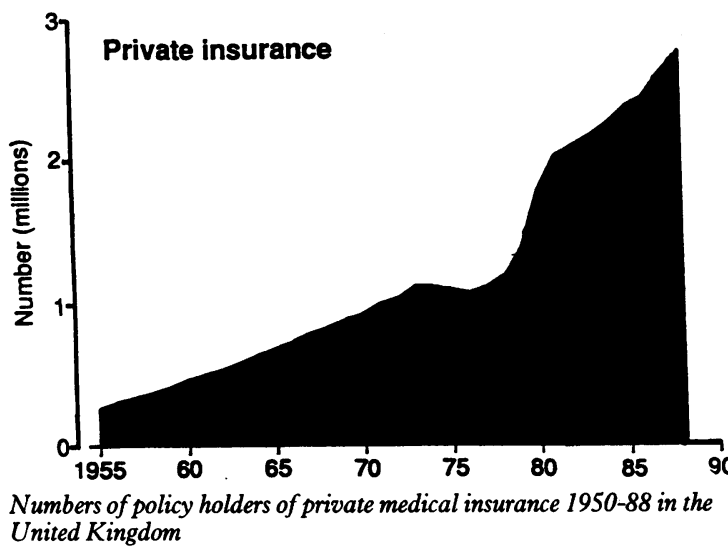

private room and a television. The care would be no better-perhaps worse" Said another patient: "The buildings are nicer, the queues are shorter, and the doctors have time to talk, though I think they're not so dedicated as NHS doctors."

The government makes no secret of its support for private medicine, however: under the white paper reforms private firms will be allowed to compete with NHS trusts. Government support drew American medical corporations to invest heavily in the mid-1980s. The number of British beds owned by United States corporations grew 10 -fold to about 2300 between 1979 and 1986 as United States investors predicted that Britain would become a medical haven for rich Arabian patients. Unfortunately, oil prices fell, and many Arabs chose French or German hospitals. On top of that medical competition in the United States grew severe, and the Americans were forced to retreat home to save their assets. By 1988 American owned beds had fallen to about 1600 .

Even with cautious doctors, however, the private sector probably will grow. British businesses are betting on it. Norwich Union last year invested $57 \mathrm{~m}$ in a new medical insurance plan, and Lloyds Bank and Leeds Permanent Building Society began offering plans last autumn.'

1 Laing W. Review of private healthcare 1989/90. London: Laing and Buisson, 1988.

Medical Manpower and Education Division, DHSS. Medical and dental prospects in the NHS in England and Wales in 1988. Health Trends 1989;21:158-76.

3 Higins J. The business of medicine: private health care in Britain. London: Macmillan Education, 1988.

4 Open University. Caring for health: dilemmas and prospects. Milton Keynes: Open University Press, 1985.

5 Woods R. Choice of private medical cover grows wider. Sunday Times 1990; Oct 7:4-11. 